\title{
PerCursos
}

\section{Identidade feminina e espaço no conto A Velha, de Marília Arnaud}

\begin{abstract}
Resumo
Este artigo tem como objetivo analisar as construções de sentido decorrentes da relação espaço/personagem no conto A velha, de Marília Arnaud, investigando como a prostituta da narrativa vivencia a força dos referenciais simbólicos ligados ao corpo e à cultura, cujas formas de atuação interferem de modo decisivo na trajetória da protagonista em sociedade. Para tanto, utiliza-se como base a Topoanálise, termo inicialmente criado por Bachelard (2000) para indicar os estudos dos valores que compõem a interioridade do sujeito da construção literária. Posteriormente, esse método assumiu maior abrangência através dos estudos de Borges Filho (2007), passando a compreender as diversas relações estabelecidas entre a personagem e os elementos e sujeitos outros circundantes, evidenciando: percepções, sentimentos, afetos, relações sociais e culturais dentro do intrincado da estrutura narrativa. Como embasamento teórico, utilizamos, além dos autores já citados, Osman Lins (1976), Chevalier e Gheerbrandt (2012). Vale salientar que o corpo enquanto materialidade das vivências sociais e psíquicas pode ser considerado espaço sensível e fundamental para acompanhar o sujeito e suas relações espaciais. Fica evidente, portanto, que essa narrativa aborda a complexa relação entre espaço e identidade da mulher idosa e ratifica a condição histórica e social do corpo feminino nos espaços que o abarcam. Além disso, observa-se que a interpretação da tessitura narrativa a partir da metodologia citada auxilia na percepção mais profunda da potencialidade estética do conto.
\end{abstract}

Palavras-chave: Literatura Contemporânea. Espaço. Identidade. Arnaud, Marília.

\author{
Risonelha Sousa Lins \\ Doutora em Letras na \\ Universidade do Estado do Rio \\ Grande do Norte - UERN. \\ Professora do Instituto Federal \\ de Educação, Ciência e \\ Tecnologia da Paraíba - Campus \\ Sousa. \\ Brasil \\ risonelha@gmail.com
}

\footnotetext{
Para citar este artigo:

LINS, Risonelha Sousa. Identidade feminina e espaço no conto A Velha, de Marília Arnaud. PerCursos, Florianópolis, v. 21, n.47, p. 153 -170, set./dez. 2020.
} 


\title{
Female identity and space in the short story the Elderly Woman, by Marília Arnaud
}

\begin{abstract}
This article aims to analyze the constructions of meaning resulting from the space/character relationship in the story A Velha, by Marilia Arnaud, investigating how the prostitute in the narrative experiences the strength of symbolic references linked to the body and culture, whose forms of performance decisively interfere in the protagonist's trajectory in society. To this end, Topoanalysis is used as a basis, a term initially created by Bachelard (2000) to indicate the studies of the values that make up the interiority of the subject of literary construction. Subsequently, this method assumed greater scope through the studies of Borges Filho (2007), beginning to understand the various relationships established between the character and the elements and subjects surrounding others, showing: perceptions, feelings, affections, social and cultural relations within the intricate of the narrative structure. As a theoretical basis, we use, in addition to the authors already mentioned, Osman Lins (1976), Chevalier, and Gheerbrandt (2012). It is worth mentioning that the body as a materiality of social and psychic experiences can be considered a sensitive and fundamental space to accompany the subject and his spatial relationships. Therefore, it is evident that this narrative addresses the complex relationship between space and the older woman's identity and confirms the historical and social condition of the female body in the spaces that encompass it. Besides, it is observed that the interpretation of the narrative fabric from the methodology mentioned above helps in the deeper perception of the aesthetic potential of the story.
\end{abstract}

Keywords: Contemporary Literature. Space. Identity. Arnaud, Marília. 


\section{Considerações iniciais}

A escritora contemporânea Marília Arnaud vem ganhando as atenções dos leitores e estudiosos da literatura pelos modos de configuração dos conflitos existenciais dos sujeitos pós-modernos e as relações socioculturais entre os gêneros. Autora de quatro livros de contos: Sentimento Marginal (1987), A menina de Cipango (1994), Os campos noturnos do coração (1997), O livro dos afetos (2005) e três romances: Suíte de silêncios (2012), Liturgia do fim (2016) e O pássaro secreto (2020)1, Arnaud evidencia o peso dos valores e preconceitos enraizados na mente humana que norteiam as relações interpessoais em sociedade, bem como os reflexos sociais dos desencontros afetivos os quais beiram à obsessão, à violência ou geram o apagamento do indivíduo.

Pertencente a sua segunda obra, A menina de Cipango, o conto "A velha" aborda a trajetória de uma prostituta idosa que continuamente atravessa o espaço urbano até uma caixa d'água vazia onde se encontra com o único cliente que lhe resta. Durante seu percurso, devido ao ser corpo envelhecido, ela é aviltada por um grupo de adolescentes que estuda em uma escola de religiosos.

A protagonista, anônima no enredo, transita sob o peso dos papéis de gênero, orientados pela disciplinarização do corpo (FOUCAULT, 1987) e pela fuga desse confinamento do eu dentro da tecnologia dos gêneros. Numa narração rápida e direta é possível acompanhar a prostituta, cujo corpo concretiza os estereótipos ligados à velhice feminina e às posições sociais e localizações do indivíduo em sociedade. Além disso, verifica-se o aprisionamento da personagem numa conjuntura de pobreza e marginalidade, pois a velha se prostitui por falta de recursos financeiros, agravando cada vez mais as desigualdades sociais e de gênero, operadas através dos padrões tradicionais de comportamento, nos preconceitos de classe e de gênero.

\footnotetext{
${ }^{1}$ Referências: ARNAUD, Marília. Sentimento marginal: contos e crônicas. João Pessoa: Gráfica Santa Marta, 1987.

ARNAUD, Marília. Os campos noturnos do coração. João Pessoa: Editora Universitária, 1997. ARNAUD, Marília. O livro dos afetos. Rio de Janeiro: 7Letras, 2005

ARNAUD, Marília. Suíte de silêncios. Rio de Janeiro: Rocco, 2012.

ARNAUD, Marília. Liturgia do fim. São Paulo: Tordesilhas, 2016.

ARNAUD, Marília. 0 pássaro secreto. Amazon, 2020. E-book Kindle. Disponível em: https://www.amazon.com.br/p\%C3\%A1ssaro-secreto-Mar\%C3\%ADlia-Arnaud-ebook/dp/Bo8L8JBGYJ
} 
Schmidt (2012) ressalta que o corpo feminino é visto através de mediações ligadas à compreensão dos constructos culturais, portanto não se refere ao sujeito em si, mas à visão simbólica sobre ele construída no contexto social. Nesse sentido, pode-se dizer que o julgamento moral e a condenação da personagem no conto arnaudiano ironizam a redução da essência da mulher à corporalidade, evidenciando uma totalidade psíquica e social que se firma no contato com outros sujeitos.

Na verdade, torna-se impossível dissociar a história das mulheres do seu lócus de atuação social: o corpo, uma vez que a feminilidade e os processos de construção da identidade estão ligados tanto ao olhar processado sobre elas, quanto aos modos de negociação estabelecidos nos contextos de relações particulares. Assim, da mesma forma que outras escritoras e artistas visuais, Arnaud tenta denunciar, através da arte, a propagação de padrões e preconceitos que mantêm as mulheres encarceradas numa política cultural do corpo biológico.

Conforme a crítica de arte Griselda Pollock (1996), nas representações ligadas aos novos feminismos, as reivindicações inerentes à sexualidade feminina, as lutas de combate à violência, à pornografia e o direito à expressão do desejo e da fantasia em qualquer idade se expressam por meio do corpo, elemento social e psicologicamente construído. Isso implica dizer que a mulher interage subjetivamente com os espaços por meio do corpo, cuja superfície se torna linguagem.

Na mesma linha de pensamento, Grosz (2011, p. 89), discutindo a relação recíproca entre as experiências do sujeito no espaço urbano e a construção de interioridade psíquica, enfatiza que "a corporalidade na sua especificidade sexual, pode ser vista como a condição material da subjetividade", ou seja, os modos como o sujeito assimila as relações com o espaço influem nas suas disposições íntimas e visões de si mesmo, assim como inscreve no corpo e nas condutas sociais o seu interior psíquico.

Com relação à mulher idosa, é importante ressaltar o fato de que suas representações correspondem, na maioria das vezes, a clichês da cultura patriarcal, nos quais figuram como indivíduos desguarnecidos da sexualidade, resignados à condição que Ihes impõem os familiares, ou condizem a sujeitos anulados pelos estereótipos 
criados para a velhice feminina dentro das relações sociais. A respeito dessa visão preconceituosa, Simone de Beauvoir (1990), em sua obra A velhice, assevera que a senectude não se constitui apenas num fator biológico, mas corresponde a um processo que envolve as relações históricas e sociais do sujeito, produzindo efeitos mais abrangentes. Essa autora ressalta, ainda, que a desvalorização ligada ao corpo feminino envelhecido associa-se ao fato de a mulher ser considerada em prol do desejo masculino, elemento de posição central das relações de gênero de acordo com os princípios da casa patriarcal, pois “já que o destino da mulher é ser, aos olhos do homem, um objeto erótico, ao tornar-se velha e feia, ela perde o lugar que lhe é destinado na sociedade: torna-se um monstrum que suscita repulsa e até mesmo medo [...]" (BEAUVOIR, 1990, p. 152).

Com base no que foi exposto até aqui, este artigo tem como objetivo analisar as construções de sentido decorrentes da relação espaço/personagem no conto mencionado nesta introdução. Para tanto, utiliza-se como base a Topoanálise, método de crítica literária em que a personagem é analisada com base na sua relação com o espaço com o qual interage, levando em conta não apenas os aspectos sociais, mas também o psicológico, cultural, histórico, afetivo e filosófico ligado à experiência do sujeito. Intentamos com essa leitura alcançar maiores significações ligadas aos desejos, às opressões e às subjetividades da protagonista dessa construção narrativa, que circula na contramão dos discursos dominantes, no interior dos quais a dimensão humana torna-se imperceptível.

\section{Atravessando os sentidos do conto "A velha"}

O conto "A velha” inicia-se com a descrição de uma rotina de mobilidade e trânsito da personagem pelo espaço urbano feita por um narrador heterodiegético, cujo olhar se desloca entre a idosa e um grupo de adolescentes nos quais a personagem desperta curiosidade. Orientados por uma cultura sexista, na qual o homem pode exercer livremente sua sexualidade e a mulher não, os jovens reverenciam o sujeito masculino que insulta a personagem de “desgraçada”, logo após a relação sexual. 
Em nome de um padrão internalizado de comportamento, esse mesmo grupo decide punir a mulher com pedradas até que Ihe vazam um dos olhos. Essa atitude, claramente codificada em relação intertextual com o episódio bíblico de João 8: 1-11, em que os mestres e os fariseus da nação judaica trazem um casal pego em adultério para ser apedrejado mediante as palavras de Moisés; isentam, porém, o homem da culpa e condenam a mulher, cuja vida é salva porque o mestre Jesus aponta as falhas de tal julgamento.

Numa atitude que se assemelha e ao mesmo tempo se diferencia do texto sagrado, os cinco adolescentes que seguem a velha pela cidade tratam-na como matéria, subtraindo-lhe o direito de ser vista enquanto sujeito, em sua condição humana. Preocupados em julgar sua aparência, eles questionam se ela ainda tinha projetos de vida, diante da morte dos parentes e da idade que sobre ela se impunha: "tentavam adivinharIhe a idade, os parentes mortos, os sonhos, se ainda os tinha. Fabulavam a seu respeito" (ARNAUD, 1994, p. 63).

Nesse percurso de análise, constata-se que a cidade, como afirma Grosz (2011, p. 98) funciona como lugar de "produção e circulação do poder", ora garantindo que as ideologias sejam internalizadas em nome da compatibilidade social, ora excluindo os sujeitos marginalizados. A cidade, portanto, constitui-se no espaço de ratificação da identidade a partir das experiências individuais com as formas coletivas. Assim, do longo itinerário das ruas que a personagem atravessa - "subindo e descendo, avançando e cruzando avenidas, apertando-se entre a multidão murmurante" (ARNAUD, 1994, p. 64) , emana o insulamento da idosa e o seu desejo de escapar da sedimentação dos discursos opressores que limitam suas ações no espaço urbano. Entretanto, embora a coletividade a sufoque, "apertando", e os discursos sussurrados pelo povo the apontem falhas, críticas, censuras, a personagem insiste em seu objetivo de vida.

Logo, percebe-se no conto o estreitamento de espaços, uma vez que o drama da personagem ocorre, inicialmente, no amplo das ruas centrais, depois continua em "uma estradinha de barro" (ARNAUD, 1994, p. 64) e finaliza em uma caixa d’água abandonada. $\mathrm{E}$, como não existe um espaço que abarque a protagonista ou a favoreça, a rua é o lugar onde se constitui e no qual tenta firmar uma individualidade transgressora. Para a velha, 
assim como para outros indivíduos hostilizados e discriminados pela sociedade, o espaço urbano é fonte de angústia, exílio, tensão. Assim, o fato de caminhar na cidade, longe de indicar um reconhecimento das modificações operadas nos lugares de suas vivências, traduz-se no:

processo indefinido de estar ausente e à procura de um próprio. A errância, multiplicada e reunida pela cidade, faz uma imensa experiência social de privação de lugar -_ uma experiência, é verdade, esfarelada em deportações inumeráveis e ínfimas (deslocamentos e caminhadas), compensada pelas relações e os cruzamentos desses êxodos que se entrelaçam, criando um tecido urbano, e posta sob o signo do deveria ser, enfim, o lugar, mas é apenas um nome, a Cidade. (CERTEAU, 1998, p. 183).

Dessa feita, como andarilha, a idosa sofre uma espécie de banimento que dá origem a carências e fugas, ao mesmo tempo em que fica exposta a todo tipo de ação que ameaça a própria integridade. É o desamparo das ruas que faz progredir a violência contra a protagonista. A princípio, ela se torna alvo dos garotos da escola de religiosos que a elegem como objeto de investigação e ao mesmo tempo a discriminam pelo corpo decadente: "riam dela e teciam chacotas a sua passagem" (ARNAUD, 1994, p. 63). Suportando em silêncio os comentários constrangedores dos jovens sobre sua individualidade e condição social, a mulher consente com a violência simbólica. Para Bourdieu (2012), esse tipo de violência dilui-se no cotidiano das vítimas, porque se manifesta de maneira sutil, normalmente pela linguagem, atingindo os princípios de identificação e individualidade. Quase sempre a vítima não reage, aceitando a posição inferior oferecida pelo sujeito que oprime.

Na narrativa em análise, fica evidente que, como a velha não pode procriar, não se adéqua ao ideal de beleza eleito e glorificado pela sociedade, é vista como um produto fora do prazo de validade, submetendo-se a uma relação hierárquica de classe e de gênero que a intimida. Por sua vez, o narrador do conto corrobora a visão desfavorável da protagonista, descrevendo-a com uma imagem deformada: "perfil afilado e rugoso", “corpo de carnes escassas", "seios secos" (ARNAUD, 1994, p. 64), aproximando-a da 
visão cultural da velhice, ou seja, a personificação desagradável da morte ou obstáculo descartável.

A personagem se desloca do lar, ao qual se agregam as mulheres puras, submissas, para ser vista na rua, espaço considerado exclusivamente masculino. Nesse terreno proibido, ela sofre não só opressões econômicas e de classe, mas também social e psicológica. Anulada pelos preceitos sociais subjugadores, internalizados tanto pelos jovens quanto pelo parceiro sexual, ela caminha num terreno movediço de existência, equilibrando-se nos direitos de exercer a subjetividade.

Sem nome, sem lar ou amigos, é apenas a velha, solitária, a caminhar "com uma agilidade de mulher jovem e carregando uma maleta de mão, vazia talvez pela facilidade com que a balançava para frente e para trás num ritmo de pêndulo de relógio" (ARNAUD, 1994, p. 63), no intuito de prostituir-se.

De acordo com Roberts (2009), a visão excludente das meretrizes originou-se na oposição entre a autonomia financeira e sexual destas e a confirmação da autoridade patriarcal, defendida pelo Cristianismo e pelo Islamismo. Para essa autora, à medida que os dogmas dessas religiões iam se difundindo e o domínio masculino aumentando, as prostitutas eram cada vez mais consideradas anormais, contrárias à moralidade e incapazes de exercer a cidadania.

Sob esse olhar preconceituoso da sociedade patriarcal, a prostituta da narrativa vivencia a força dos referenciais simbólicos ligados ao corpo e à cultura, cujas formas de atuação interferem de modo decisivo na sua trajetória. Nessa perspectiva de relação entre corpo e sociedade, Foucault (2008) ressalta que o corpo se constitui no alvo dos mecanismos estruturais de poder que sutilmente ajustam gestos, condutas e instituições e situa o sujeito dentro do complexo de relações no espaço em que está inserido.

Com base nessas considerações, entende-se que a narrativa aponta para o preconceito como uma força ideológica que se impõe sobre a personagem, impedindo-a de viver a sua condição humana e reforça a ideia de a mente, o corpo e o espaço estarem intimamente relacionados na constituição da identidade. Logo, pode-se dizer que a protagonista desse conto é mutilada por desafiar os preceitos sociais de existência que 
norteiam os atos do ser em devir, esforçando-se para superar as próprias limitações e viver a subjetividade.

A memória de um corpo jovem movimenta a idosa para a vida, ainda que as mudanças impiedosas da idade se operem no estado do seu corpo. Além disso, as marcas das experiências, escolhas e ações que a constituem se fixam nos espaços e metaforicamente são representadas pela maleta, onde guardava seu vestido branco e suas roupas íntimas no momento em que se prostituía.

Nota-se pela forma cuidadosa como dobrava e guardava as roupas antes do sexo, uma necessidade de registrar uma interioridade não corrompida pelas relações sociais, posto que, de acordo com Chevalier e Gheerbrand (2012), a cor branca carrega, paradoxalmente, a ideia de soma e ausência, pondo em destaque a vida da velha pautada na soma de experiências e subtrações, ligadas tanto às carências econômicas, quanto aos atributos físicos de beleza. No sentido mais amplo, pode-se afirmar que o vestido representa a castidade, elemento exigido para a conduta feminina dentro das convenções sociais do Patriarcalismo. Ao desvesti-lo, a idosa executa uma desapropriação do modelo identitário aos olhos da sociedade, causa de sua condenação. Vejamos a cena:

Ela parecia respirar com dificuldade, enquanto, lenta, ia despindo-se. Primeiro livrou-se de toda brancura do vestido e em seguida do que vinha por baixo, uma camiseta, uma anágua e uma calçola que the chegava quase aos joelhos. Nua agachou-se, recolheu e dobrou as peças de roupa, guardando-as depois na maleta de mão. De pé, arrastou num gesto débil a marrafa dos cabelos e estes, longos, largaram-se sobre o corpo de carnes escassas. Restou um crucifixo entre os seios secos (ARNAUD, 1994, p. 64).

No trecho acima, observa-se todo um ritual de transformação da personagem, mas o gesto sedutor de soltar os cabelos sobre a nudez vem acompanhado da descrição pejorativa do narrador, fechando-se a cena no símbolo da religiosidade cristã católica, o crucifixo. Os adjetivos utilizados para descrever o físico da protagonista já enfatizam uma falta, confirmando a supressão de atributos satisfatórios à feminilidade desejável. Além disso, o olhar do narrador fixa-se, simbolicamente, numa cruz que divisa a cabeça dos 
demais membros do corpo. Esse objeto está ligado à ideia de sacrifício, negação dos prazeres da carne em nome de uma espiritualidade ligada ao Cristo.

Como elemento que marca a orientação existencial do homem (CHEVALIER; GHEERBRANDT, 2012), infere-se que a cruz salienta o impiedoso juízo da sociedade contra a libido das idosas, uma relação sacrificial do corpo, uma imposição do comportamento assexuado.

Em torno desse padrão de recato e de autonegação, a personagem é julgada e condenada ao apedrejamento pelos jovens que a seguiram ao longo da cidade e agora se sentem "perturbados pela visão singular" (ARNAUD, 1994, p.65) da relação sexual empreendida. Não havia, porém, quem pudesse defendê-la, posto que seu discurso não era valorizado e não dispunha de recursos suficientes para resistir à opressão.

Vale mencionar que o universo subjetivo puro, intocado pelas decepções e desajustes externa-se através do gesto expansivo de dançar e cantarolar uma "canção infantil, de menina em roda, a voz forte e melodiosa, a cabeça pendendo para lá e para cá" (ARNAUD, 1994, p. 65). Portanto, deduz-se que, embora a personagem necessitasse prostituir-se para sobreviver, a relação sexual reveste-se de um sentido emblemático à medida que traz de volta, ainda que momentaneamente, a visão do corpo desejado, alimentando a alegria em detrimento dos dissabores relacionados aos valores externos ao sujeito. Para Merleau-Ponty (1999, p. 215), o corpo exterioriza as necessidades do eu e a sexualidade funciona como um estímulo às faculdades internas do sujeito, pois:

É preciso que exista, imanente à vida sexual, uma função que assegure seu desdobramento, e que a extensão normal da sexualidade repouse sobre as potências internas do sujeito orgânico. É preciso que exista um Eros ou uma Libido que animem um mundo original, deem valor ou significação sexuais aos estímulos exteriores e esbocem, para cada sujeito, o uso que ele fará de seu corpo objetivo. (MERLEAU-PONTY, 1999, p. 215) 
Considerando as palavras de Merleau-Ponty, inferimos que a consciência da desvalorização do sujeito no espaço de relações sociais afeta a autoestima dos idosos, pois a validação social é imprescindível para a relação dialógica entre os sujeitos.

Sabe-se que, durante muito tempo, a sexualidade feminina esteve limitada aos relacionamentos propostos pelo casamento e, apesar de as conquistas em relação ao usufruto do corpo terem se tornado mais evidentes na contemporaneidade, o exercício da sexualidade na senectude é considerado despudor. Destarte, considera-se que, embora o corpo maduro não apresente tantos atrativos quanto os mais jovens, o exercício da sexualidade é válido, devendo ser visto sem juízos condenatórios ou como impróprios.

Sobre esse descrédito atribuído pela sociedade ao corpo envelhecido, Lima (2007, p. 99) explica que "há um forte estigma que desvaloriza a mulher mais velha. Normalmente a vida sexual de uma mulher mais velha é alvo de chacotas, comentários, especialmente quando se trata de um relacionamento com homem mais jovem". Ou seja, a sociedade ainda não vê como natural a sexualidade da mulher idosa, fazendo recair sobre aquelas que desafiam os padrões morais prescritos pelo sistema patriarcal a forte carga de preconceito que pode gerar diversos tipos de violência. Fica evidente, por conseguinte, que a personagem luta contra as reações exteriores às mudanças do corpo e reage a uma interioridade que anule os seus desejos e necessidades.

Nessa mesma perspectiva, Silva, Soares e Assman (2003) enfatizam que o corpo constitui-se num espaço no qual os papéis sociais, culturais, de gênero e sexualidade de um povo se confirmam, espelhando os valores que estão arraigados na sua mentalidade. Para esses autores: "O corpo pode ser pensado como território polissêmico e idiossincrático, como traço continuamente redesenhado pela cultura, [...], tela sensível onde se desenrola a vida e também a morte" (SILVA, SOARES e ASSMAN, 2003, p. 268). Neste sentido, a sociedade moderna propõe a sensualidade feminina nos moldes de um corpo jovem, bem torneado e útil ao consumismo capitalista, do qual a mulher idosa se exclui, restando-lhe um cotidiano de holocausto. Isso fica bem claro no conto em questão, pois há uma repulsa ao corpo feminino metamorfoseado pelo tempo e a sexualidade lhe é indeferida. 
Para Grosz (2015), o corpo está sujeito à consciência e funciona como a linguagem do sujeito e, dentro das percepções históricas e filosóficas, foi desvalorizado e associado às mulheres, o que contribuiu para inferiorizar o universo feminino em relação ao masculino, associado à mente. Essa autora enfatiza que a visão dualista limitou o desenvolvimento social das mulheres, garantindo a desigualdade entre os gêneros. Por esse motivo, as feministas consideram as problemáticas referentes ao corpo importantes na análise das ideologias ligadas ao comportamento da mulher. Essa desigualdade fica bem evidente no conto, uma vez que em nenhum momento o homem loiro que usufrui do corpo da idosa é julgado, nem são consideradas as circunstâncias que mantêm a personagem na prostituição.

Ora, sendo a identidade um processo social intermediado pelas relações intersubjetivas de sujeitos historicamente localizados, faz-se sempre necessária uma confirmação dos modos de ser social e cultural do indivíduo (CANDAU, 2011), por isso a identidade da velha senhora não se adéqua ao espaço sociocultural em que se insere, permanecendo em crise. Isso porque o espaço geográfico absorve uma ideologia que não condiz com a psique da personagem, ao mesmo tempo em que a desloca para o espaço de marginalidade por ser desprovida de recursos financeiros e prostituir-se.

Do amplo espaço das ruas, onde se vislumbra uma identidade rasurada, a personagem mergulha em "uma estradinha íngreme de barro" e um lugar quase desértico, "com ausência de pessoas e habitações" (ARNAUD, 1994, p. 64), onde não há mais nenhuma perspectiva de desvio até deter-se numa “caixa d'água” de concreto, em que ela se desnuda, levando os rapazes a acreditar que fosse banhar-se.

Esse percurso é marcado pelo alto/ baixo, inferior/superior, como se observa nas expressões: “subindo e descendo”, “ergueu-se”, “desceram e tornaram a subir”. Trata-se de uma relação em que os antagonistas se posicionam de forma mais elevada que a mulher, o que favorece o julgamento negativo efetuado.

No espaço vazio da caixa d'água, a velha expõe seu corpo e seus desejos e, quando sai para o espaço aberto, é apedrejada, provando que as dificuldades e o sofrimento não estavam apenas nas mudanças do corpo, mas também nas relações 
sociais e no comportamento alheio a qualquer empatia às vivências do outro. A presença dos adolescentes curiosos, portanto, transforma o cenário de vivências da personagem, causando, inevitavelmente, violências e perdas.

Os garotos movimentam-se numa escada de onde lançam as pedras. A escada, apontada por Chevalier e Gheerbrandt, (2012) como símbolo de ascensão e, consequentemente, de poder, aparece no enredo, galgada pela personagem de modo descendente até ser visualizada de cima para baixo, "no fundo da caixa" (ARNAUD, 1994, p. 65).

Esse olhar de cima para baixo sobre a personagem revela a superioridade dos discursos sociais sobre o estado de ser e sentir das idosas, que vivem o conflito entre o particular/social, o interior/exterior e permanecem atadas aos princípios estéreis da sociedade patriarcal. Ironicamente, é o pôr do sol que faz a personagem abandonar a maleta no solo, fato que nos faz ver que a sociedade impõe à mulher a percepção da velhice como um processo desvirtualizante do eu, retirando do indivíduo a capacidade de desfrutar das possibilidades da existência, impondo a mudança da aparência física e o declínio da habilidade de produção.

Sendo a caixa o símbolo do universo feminino, remetendo ao corpo e à mente, numa relação que esconde o mistério, a fragilidade e o medo que constituem a mulher, e a água, elemento purificador (CHEVALIER; GHEERBRANT, 2012), entende-se que na ausência de líquido na caixa d’água, registra-se o declínio involuntário e irreversível do corpo, no qual se imprimem as marcas das censuras da sociedade e suas implicações psicológicas na trajetória da mulher, não havendo formas de luta que lhe garantam fugir de tal situação.

Para Osman Lins (1976), o estudo do espaço e do tempo numa narrativa permite a visão de certos aspectos da realidade que orientam as perspectivas das coisas ao mesmo tempo em que põe o leitor em contato com a personagem e suas motivações psicológicas e sociais para a ação. Logo, o espaço é um elemento importante para situar o sujeito ficcional no enredo e manter o vínculo com a realidade representada. Com base nessas considerações, compreende-se que o espaço quase desértico em que a 
personagem é violentada associa-se ao seu olhar sem brilho voltado para o alto como uma súplica ao superior, ao divino.

De acordo com Chauí (1985), quando se retira do sujeito a capacidade de ação, reificando-o e submetendo-o à inércia e à estagnação, nulifica-se a sua voz e sua existência em prol de outrem, corroborando a violência. Nesse sentido, nega-se à personagem o direito de exercer a sua individuação, sua voz é silenciada e seu corpo punido.

No desfecho do conto, enquanto uma série de pedradas castigam o corpo da mulher, vazando-lhe o olho, o narrador, conivente com o desprezo dos jovens, analisa friamente os fatos, mencionando o corpo desfigurado da idosa, coberto de sangue: "A primeira pedrada vazou um dos olhos da velha. O outro continuou grelado e medonho no rosto salpicado de sangue. As seguintes atingiram-lhe todo o corpo, esfarrapando-lhe os joelhos ossudos, os seios descarnados, o púbis de pelos ralos e embranquecidos" (ARNAUD, 1994, p. 65). Nota-se que a morte do ser e do sentir é imposta ao sujeito idoso pela sociedade, que determina os sistemas de encarceramento e rasura do sujeito feminino.

Ligado à percepção visual, o olho indica o conhecimento e a capacidade intelectual (CHEVALIER; GHEERBRANDT, 2012), por isso, ao mencionar a perda de um dos olhos na personagem, o narrador enfatiza a nulidade da capacidade de perceber o mundo ao seu derredor, imposta aos velhos pelas novas gerações. Todavia, embora tenha "o rosto salpicado de sangue" (ARNAUD, 1994, p. 65), a personagem mantém seu olho são “grelado e medonho" (ARNAUD, 1994, p. 65), ou seja, apresenta resistência, negando-se ao estado de total aniquilamento.

Dessa mesma forma, a pedra, como elemento de construção, representa a força das estruturas sociais sobre a práxis do indivíduo, coisificado e desrespeitado enquanto sujeito de sua existência. À vista disso, fica claro que o corpo, como vínculo entre a realidade externa e a consciência constitui-se em objeto de abordagem da topoanálise, no sentido de se investigar as circunstâncias que efetivam a relação entre o sujeito e os elementos que o abarcam. 
Quando o narrador desloca o olhar da velha para afirmar que os adolescentes “iniciaram o retorno para casa, pela estradinha deserta” (ARNAUD, 1994, p. 66), consegue nos lembrar de que essa atitude de exclusão é banalizada no cotidiano e que as ideologias cegamente assimiladas como modelo da realidade podem conduzir ao desprezo do sujeito humano que circula no interior das relações socioespaciais.

Para sumarizar a análise feita neste artigo, salientamos que o corpo, a sexualidade e o espaço estão intimamente relacionados na trajetória do feminino, principalmente no que se refere ao envelhecimento. Esse processo é permeado por ideias estereotipadas sobre a identidade feminina, gerando a discriminação e o esvaziamento do sujeito, que passa a habitar a extremidade da margem.

No conto “A velha", portanto, notamos que a protagonista não carrega apenas as características biológicas, mas também um fardo pesado de significações sociais e culturais que definem a identidade do feminino idoso, quase sempre punido severamente por tentar manter a integridade de suas necessidades físicas e psicológicas de ser humano.

\section{Considerações finais}

A análise do conto mencionado permite-nos identificar a complexa relação entre corpo e identidade da mulher idosa nos espaços que o abarcam. Assim, é perceptível que a personagem não se encaixa em nenhum lugar, posto que caminha em toda a trajetória da narrativa, parando apenas na caixa d'água, onde ocorre o desfecho. Há, portanto, um espaço constituído pelo próprio sujeito, que busca ressignificar corpo e alma diante das limitações físicas e sociais.

Pela topoanálise efetuada na narrativa em estudo, é possível verificar o nexo entre a personagem e as ações que conduzem o enredo, visto que a ênfase na rua cheia de pessoas e desértica apontam para a vigilância e o não-lugar relativos à trajetória da idosa nos espaços sociais. 
Dessa forma, com descrições expressionistas do corpo feminino envelhecido, Arnaud conduz o leitor a uma análise da gama de preconceito que se camufla na pretensa evolução da mentalidade social contemporânea e, através do ato agressivo efetuado pelos jovens, reflete sobre as dificuldades dos idosos em exercer a individuação nos espaços sociais.

Por meio de um narrador insensível ao drama do outro, a autora analisa o enfraquecimento das relações de empatia e respeito ao semelhante e desenha a trajetória social da mulher idosa, apontando os diversos entraves que a impedem de apreciar seu corpo, vivenciar seus desejos e sua profissão. Nesses termos é possível afirmar que as relações espaciais - que se ampliam aos conceitos de dentro, fora, inferior, superior, acima, abaixo - apontam para as possibilidades de alargamento dos sentidos da vida da personagem e, consequentemente, da história.

Enfim, ao configurar uma personagem que rompe com o paradigma da mulher sexualmente desejável, mas que articula um processo mental divergente de sua condição de dupla marginalidade, a escritora efetua uma análise das contradições das experiências do mundo moderno nos espaços urbanos, especificamente na exclusão que marca as experiências dos sujeitos periféricos e a trajetória dos gêneros.

Em síntese, ao analisar os significados da relação espaço/personagem no conto " $\mathrm{A}$ velha", procurou-se auxiliar na percepção da potencialidade estética do referido conto enquanto discussão dos padrões e estereótipos ligados ao comportamento e à sexualidade da mulher idosa, o que destaca a contribuição da literatura como instrumento de reflexões sobre o comportamento social.

\section{Referências}

ARNAUD, Marília. A velha. In: ARNAUD, Marília. A menina de Cipango. João Pessoa: A União, 1994.

BACHELARD, Gaston. A poética do espaço. São Paulo: Martins Fontes, 2000. (Coleção tópicos). 
BEAUVOIR, Simone de. A velhice. 2. ed. Rio de Janeiro: Nova Fronteira, 1990.

BÍBLIA, N. T. João. In: BÍBLIA. Português. Bíblia Sagrada: Antigo e Novo Testamentos. Tradução de João Ferreira de Almeida. São Paulo: Sociedade Bíblica do Brasil, 2008. p. 1400-1401.

BORGES FILHO, Ozíris. Espaço \& literatura: introdução a uma topoanálise. Franca: Ribeirão Gráfica e Editora, 2007.

BOURDIEU, Pierre. A dominação masculina. Rio de Janeiro: Bertrand Brasil, 2012.

CANDAU, Joël. Memória e identidade. São Paulo: Contexto, 2011.

CERTEAU, Michel de. A invenção do cotidiano. 3. ed. Petrópolis: Editora Vozes,1998.

CHAUÍ, Marilena. Participando do debate sobre mulher e violência. In: CHAUÍ, Marilena. Perspectivas antropológicas da mulher. Rio de Janeiro: Zahar, 1985.

CHEVALIER, Jean; GHEERBRANT, Alain. Dicionário de símbolos: mitos, sonhos, costumes, gestos, formas, figuras, cores, números. 26. ed. Rio de Janeiro: José Olympio Editora, 2012.

FOUCAULT, Michel. Vigiar e punir: nascimento da prisão. Petrópolies: Editora Vozes, 1987.

FOUCAULT, Michel. Microfísica do poder. 26. ed. Rio de Janeiro: Graal, 2008.

GROSZ, Elizabeth. Corpos reconfigurados. Cadernos Pagu, Campinas, n. 14, p. 45-86, 1 jun. 2015.

GROSZ, Elizabeth. Corpos-cidades. In: GÊNERO CULTURAL, VISUAL E PERFORMANCE: antologia crítica. Ribeirão: [s.n.], 2011. p. 89-100. Disponível em: https:/l repositorium.sdum.uminho.pt/bitstream/1822/23585/1/

Genero\%20Cultura\%Visual\%20Performance.pdf . Acesso em: 17 de novembro de 2020.

LIMA, Susana M. A obscenidade da velhice feminina: rompimento do olhar na literatura. In: SILVA, Cristiani Bereta da; Silva; ASSIS, Gláucia de Oliveira; Assis; KAMITA, Rosana C. Kamita. (org.). Gênero em movimento: novos olhares muitos lugares. Florianópolis: Editora Mulheres, 2007. p. 99-109.

LINS, Osman. Lima Barreto e o espaço romanesco. São Paulo: Ática, 1976. 
MERLEAU-PONTY, Maurice. Fenomenologia da percepção. 2. ed. São Paulo: Martins Fontes, 1999.

POLLOCK, Griselda. Inscriptions in the Feminine. In: DE ZEGHER, Catherine (dir.). Inside the visible, an elliptical traverse of the 20th century art. London: MIT Press, 1996.

ROBERTS, Nickie. As prostitutas na história. Rio de Janeiro: Rosa dos Tempos, 2009.

SCHMIDT, Rita Terezinha. Para além do dualismo natureza/cultura: ficções do corpo feminino. Organon- Revista do Instituto de Letras da UFRS, Porto Alegre, v.27, n.52, 2012.Disponível em: https://seer.ufrgs.br/organon/article/view/33480. Acesso em: 17 nov. 2020.

SILVA, Ana Márcia; SOARES, Carmem Lúcia; ASSMAN, Selvino. A valorização do corpo e as falácias de um novo arquétipo da felicidade humana. In: ESTUDOS INTERDISCIPLINARES EM CIÊNCIAS HUMANAS. Florianópolis: Cidade Futura, 2003.

Recebido em: 30/06/2020 Aprovado em: 21/12/2020

Universidade do Estado de Santa Catarina - UDESC Centro de Ciências Humanas e da Educação - FAED

PerCursos

Volume 21 - Número 47 - Ano 2020 revistapercursos@gmail.com 